\title{
Performance profiles of exterior fire protective building envelopes
}

\author{
Tobias Jarnskjold, Geir Jensen and Atle Knudsen
}

COWI AS Grenseveien 86, Norway

\begin{abstract}
The fire protective envelope of any building consists of multiple elements with widely differing properties relating to a fire, such as glass, roof tiles and sheathings, wood cladding, gaps and openings. Where resistance to an exterior fire is required, all elements should be verified to provide a comparable risk of burn-through.

Elements are rated by either the material response to fire or fire resistance. In Europe, cladding sheets and wall membranes can be rated by $\mathrm{K}$ classes, which effectively include a measure of the time to burn through. A determination of burn-through time of each element of a specific building envelope should be obtained.

A design tool to verify the performance of a building's fire protective envelope has been developed. In this paper, a general description of passive elements of the envelope, which should be included in a risk assessment tool such as an index method, is presented. An illustrative approach to visualise the profiles for areas densely spaced structures where an exterior fire may trigger building-to-building fire spread is also included.

The research is based on the hypothesis that a relatively subtle and pointed upgrading of an exterior building envelope will severely reduce the speed of building-to-building fire spread, thus allowing firefighting efforts to get on top of the situation. For a burning structure to expose other buildings to fire, the fire has to settle, which leads to a burn-through to the inside. Once inside, an enclosure fire needs to develop and burn through the roof or break one or more large window panes. It is estimated that a 5-10 min delay for a structure to expose other structures to fire can be sufficient to avoid loss of multiple structures. A 1050 min burn-through time allows for an extended intervention by the fire brigade, which is significant in rural areas. A fire protective envelope may prevent an exterior fire from penetrating the protective envelope at all and the structure can be saved.
\end{abstract}

\section{INTRODUCTION}

Exterior fires and wildland urban interface (WUI) fires are global challenges and subject to increasing interest due to the emerging risk from climate change. This type of fire is hard to prevent and threatens communities that are vulnerable to exterior fires. Economic losses are mainly related to structural losses. A general approach is to reduce the potential for ignition by hardening the exterior of structures [1]. The US and Australia are familiar with such fires and have established regulations to prevent structural losses due to exterior fire events, referred to as WUI fires. In these countries, the standards NFPA 1144 "Reducing structure ignition hazards from wildland fire" [2] and AS 3959 "Construction of buildings in

This is an Open Access article distributed under the terms of the Creative Commons Attribution License 2.0, which permits unrestricted use, distribution, and reproduction in any medium, provided the original work is properly cited. 

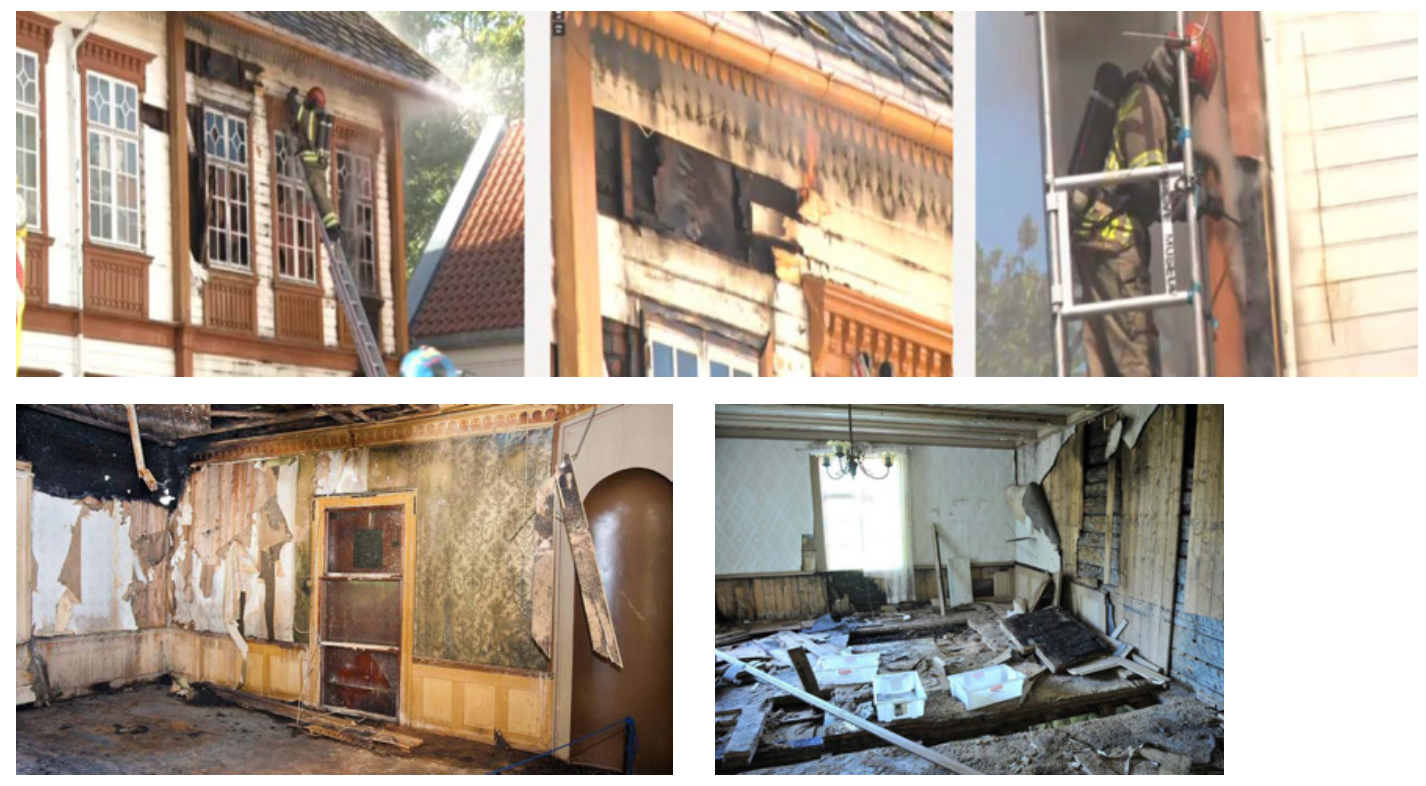

Figure 1. An exterior fire led to an indoor fire at Ringve Museum.

bush fire prone areas" [3] include requirements for the surrounding area and the building structure. The Nordic countries have less focus on this type of fire, since such events have been rare there.

However, in 2014, three fires with WUI characteristics occurred. Two of these occurred in Norway during the winter, namely the fires of Lærdal $[4,5]$ and Flatanger [6]. The third fire occurred in Sweden during July and August. These fires have increased the focus on exterior fire protection and motivated the work of a master thesis in 2015 [7]. The result is a first-hand risk assessment tool, which is described in general in this paper and from now on it is referred to as FireScore.

In the fall of 2015, Ringve Musical Instruments Museum was damaged by a weed burner near its facade (Fig. 1) [8]. The fire took hold in the air gap in the rain screen and spread within the gap to two floor voids, and the rescue team had to break up floors and the rain screen in multiple locations. A full-coverage fixed extinguishing system inside could not have prevented the damage caused by such an exterior fire entering through wall cavities and floor voids. Such fires can be prevented by identifying risks and systematically devising adequate, simple and strategic passive protection measures.

Mitigating the effects of exterior fire exposure on buildings in the Nordic countries has traditionally always focused on radiant heat transmission and direct flame contact. However, a report by SPFR [4] and a report on the Witch and Guejito fires in the US [9] indicate that a fire spread by firebrands is underrated in regard to exterior fires since firebrands are often the source of the fire spreading to other buildings and structures.

Adapting regulations and risk tools in Nordic countries from the US and Australia is not necessarily a good approach, since vegetation fuels, the climate and the occurrences of such events are different. Still, wildland fires are an increasing problem all over the world and protective measures are needed. The Norwegian Institute of Bioeconomy Research (NIBIO) has highlighted the problem and requested tools and regulations to protect built areas with dense natural vegetation [10]. Regarding forest fires, the focus in Norway has been on loss of forest, though the economic loss to buildings can be as large. Forest fires are natural events in an ecosystem. However, when built environments including infrastructures are threatened, adequate protection is required. 


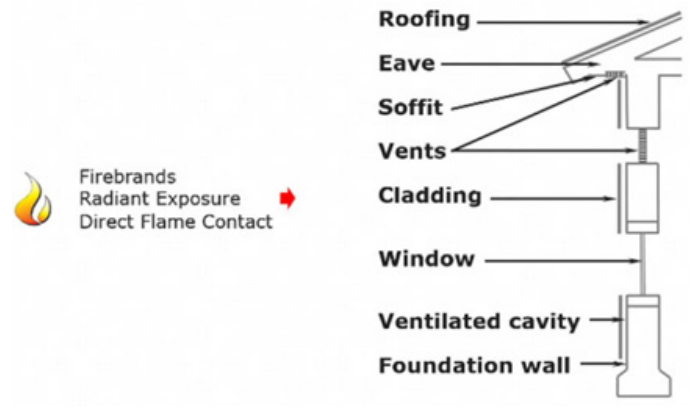

Figure 2. The fire protective envelope.

Active measures to prevent the spread of forest fires have been the common approach for decades. However, passive measures to harden structures might be more cost-effective and robust while allowing natural loss of vegetation.

Over the years, several types of risk assessment tools have been developed. Examples are given in [11]. However, none of these tools takes into account a building's response to exterior fire exposure. It must be mentioned, as indicated by Cohen [12], that risk scores resulting from these tools rate the potential loss of buildings rather than predicting the loss. It is assumed that lowering the risk will lead to improved chances of survival, but a guarantee can never be achieved.

Based on an index method, the developed risk and design tool FireScore is aimed at assessing the performance of single or multiple structures to resist exterior exposure to fire. The output report identifies and visualises weak spots of any single structure or of an area with multiple structures, which subsequently can be improved and upgraded.

A better understanding of exterior fire behaviour in areas of interest and an overview of the highrisk areas will in many cases eliminate the need for highly accurate real event simulations, such as by computational fluid dynamics (CFD) modelling. Such simulations demand a high level of precision and a large amount of input data and they tend to be expensive and time-consuming.

Critical elements of a given structure envelope can be graded and implemented in an index method such as by the FireScore. In this way, comparable risk value can be obtained for a structure. The method itself provides a transparent and systematic approach, which can be communicated to involved parties. Furthermore, the output is mapped and visualised. Tools like Google Maps are suited for making heatmaps to highlight occurrences. New handheld technology allows for maps to be created in the field, prior to the implementation of risk-reducing measures based on statistical analyses.

\section{THE FIRE PROTECTIVE ENVELOPE}

The risk assessment requires a set of elements that are critical in the event of an exterior fire. Main exposures and building elements are shown in Fig. 2. Hardening the fire protective envelope to extend burn-through time will increase the probability of effective fire fighting efforts in the case of a passing conflagration or other exterior exposure.

The protective envelope comprises multiple elements with widely different properties relating to a fire, such as glass, roof tiles and sheathings, wood cladding, gaps and openings. When resistance to an exterior fire is required, all elements should be verified to see if they have the same performance. In practice, some elements are classified by the material response to fire and others by a fire-resistance rating. The K-class rating takes into account surface and backing-sheet properties. Typically, one attempts to determine the burn-through times for all elements to ensure they all meet or exceed a minimum time. 


\section{MATEC Web of Conferences}

The building elements of the fire protective envelope are listed below by importance in descending order. Combustibility and burn-through time are of interest for all the building elements.

\subsection{Building elements of the fire protective envelope}

The fire protective envelope is divided into six elements: (1) roof, (2) eaves and gables, (3) walls, (4) foundation walls, (5) windows and (6) doors. Passive designs to harden the structure should increase the resistance against exterior fires. A protective envelope is evaluated by its effectiveness in respect to firebrand showers, spot fires, direct flames and radiant heat.

Roofs are the most important element of a building envelope in a wildfire [7, 13, 14]. They are vulnerable to firebrand penetration at the eaves, ridges or other vulnerable locations. The type of roofing is also important [15]. When assessing a roof, combustibility and burn-through of the roofing material should be included; e.g., Howard [13] has observed and linked the extensive loss of buildings to wooden shingles used as a roofing material.

Secondly, eaves and gables are vulnerable to penetration of firebrands through the eave vents and to fire at the exterior wall. Ventilated air gaps in the eaves or gable should be assessed. Ventilated roofs with eaves made of wood have a considerable risk of a fire spreading [16]. This is also the case in cold attics with openings for natural air ventilation. Ventilated roofs take advantage of the high pressure on the windward side and the low pressure on the leeward side in the removal of moisture and heat, and therefore, they are especially vulnerable. Protection measures are considered, for instance, in the California Building Code [17] and the Australian standard [3] in which a non-combustible mesh of maximum sizes $3.1 \mathrm{~mm}$ and $2 \mathrm{~mm}$, respectively, is implemented.

Ventilated air gaps in the rain screen of exterior walls are common in the Nordic countries of Europe. The gaps are vulnerable to firebrand penetration and direct flame contact. Flames in wall cavities may be elongated 5-10 times compared to exterior flames due to combustion and the flow in the cavities [18]. A fire established at a wall assembly has a high risk of spreading to the roof and eaves, subsequently to the attic, which often leads to total loss of the structure. Openings to rain-screen air gaps should be assessed and measures taken to prevent the ingress and spread of fire.

Crawl spaces and openings in the foundation walls must be assessed. Manzello [15] observed that firebrands accumulate in front of wall structures, igniting mulch beds and other combustible materials to threaten the further spread of the fire to the exterior of the building. Therefore, the possibility of the fire spreading into crawl spaces and the average height of the foundation wall up to ordinary wall elements should be considered.

Windows should be assessed by the type of glazing in the protective envelope, including the number of layers, glass and frame quality. Glazing is vulnerable to local heating, which results in rapid failure. Window qualities are to some extent addressed by the California Building Code [17]. The transition between the wall and window frames should also be assessed with respect to gaps and firebrand penetration.

Doors should be assessed in regards to the door leaf, the gaps between the door leaf and doorframe, and the transition between the frame and wall. Gaps of $2 \mathrm{~mm}$ or more [15] are critical and improvements are necessary.

Figure 3 shows the combination of highly fire-resistive and preventive measures for the fire protective envelope of an invaluable historic structure. It is to be protected from any conflagration of the surrounding residential buildings. Modifications of elements of the building envelope are aimed at making them fire resistive for $50 \mathrm{~min}$.

The thickness of some panels was increased from 30 to $35 \mathrm{~mm}$, and overlaps were protected by intumescent seals. Windows were protected by fire-resistant glass in the frame behind the outer glass and the door sets were upgraded. Ventilating cavity barriers rated for fire resistance were installed in the rain-screen cladding, at the eaves, at the foundation, in the walls and in the tower constructions. Hidden 

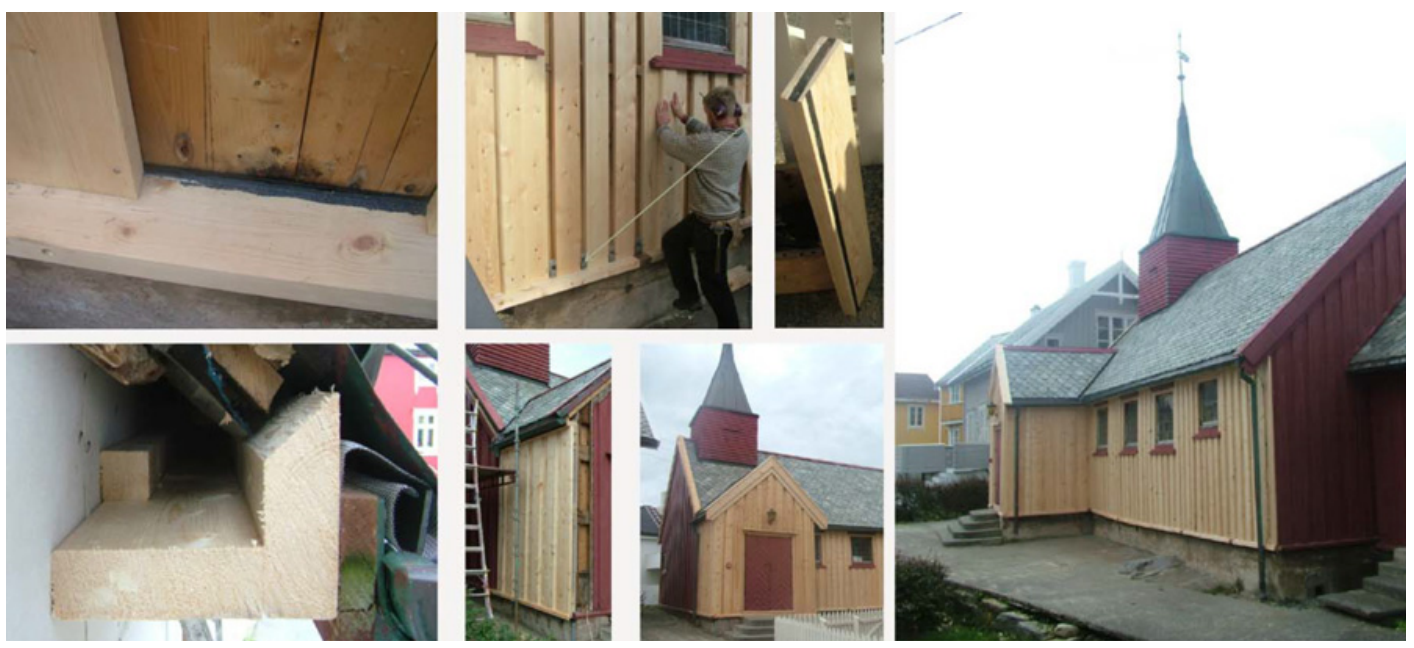

Figure 3. Pilot project [19].

battens were used to harden the eaves to extend their burn-through time. The most exposed wall has a hidden 6-mm fire-rated $\mathrm{Ca}_{2} \mathrm{SiO}_{4}$ membrane carefully located to avoid upsetting the function of the rain screen. The fire protective envelope is designed to resist exterior exposure, which is fundamentally different to exposure from room enclosure fires.

In addition to the above mentioned elements, the type of exposure varies as well. Any element of an envelope may offer different resistance to different types of exposure. Interactions between elements may also cause the overall performance to vary when exposed. For example, a roof assembly that performs well against sustained radiation and flame attack from a fire of a nearby structure may easily fail when subjected to firebrand showers from a vegetation fire further away. Glass may prevent the ingress of firebrands, but easily break in a high temperature gradient even when due to small flames. In general, unprotected openings allow the penetration of firebrands, flames and radiation, which may ignite an indoor fire in seconds.

To estimate and implement measures for a building's fire protective envelope an analysis of the exposure is required. Seven types of exposures need to be assessed and they are listed below by importance in descending order.

\subsection{Exposure elements}

The most important exposure element when assessing the spread of an exterior fire is the climate. This element can be divided in two: first, by assessing the severity and frequency of forest and wildland fires, e.g. by looking at forest or wildland fire risk indexes like the Canadian Forest Fire Weather Index [20], and second, by assessing the probability of challenging wind speeds. If the wind speed exceeds $7 \mathrm{~m} / \mathrm{s}$, which is necessary for firebrands to be lofted [15], the probability of a fire spreading over bigger distances increases.

Natural vegetation close to buildings has been shown to contribute to and increase the risk of fire spreading between buildings $[7,11,21,22]$. How a fire spreads due to vegetation is related to the vegetation's distance to the building. The space between is commonly divided into zones [23]. The amount of (natural) vegetation, the space between bushes or trees and the flammability of vegetation species should be evaluated throughout the zones. There is evidence of ignition to structures at $40 \mathrm{~m}$ from forest crown fire fronts [12]. The principles of fuel treatment are described in [21]. 
Nearby buildings also need to be considered regarding direct flame contact, radiant heat and firebrand generation. This includes sheds and annexes that are easily ignited due to their low or no fire protection. As with vegetation, the risk decreases with increasing distance between buildings.

A vegetated slope downhill of a building by a gradient exceeding $20 \%$ is associated with increased damage to the building [24]. The risk of a fire spreading also increases if the distance between the top of the slope and the building is short. In addition, this element should be considered together with wind direction and fuel.

Bridging fuels are surrounding fuels that allow a fire to spread to a building, e.g. vehicles, construction materials, hedges, wood piles, wooden porches, terraces, furniture etc., and are close or directly attached to the building. Connecting fuels affect fire exposure (treatment 19 for connecting fences [24]). This parameter should include assessing plant beds and bushes that act as a link between the ground beside the building wall and the combustible parts of the building envelope. Plant beds covered with mulch have been proven to increase base wall exposure [15].

Fire breaks are areas with incombustible surfaces that can act as a barrier to hinder or limit fire spread. Treatment 7 in [24] indicates such breaks are parking spaces, driveways, paths, roads or trails. Fire breaks do not necessarily stop a conflagration but limit the damage to buildings as they may reduce the grade of exposure. Yet, spot fires are known to occur as far as 20 kilometres from the fire front [25], also known as spotting.

Gardening and tidiness refer to the condition of orchards, flowerbeds etc. surrounding the building. By trimming hedges, bushes and trees and keeping grass short, the amount of fuel is reduced. Dry fuels are a particular concern as they may support ignition that can spread to the surroundings [23].

\section{A SYSTEMATIC RISK EVALUATION TOOL}

These elements greatly affect the risk of fire spreading and should be evaluated systematically and methodically. CFD modelling is a simulation tool, which can be used to predict the spread of an exterior fire. Fires in built environments are complex, involving many physical mechanisms. To analyse the absolute risk level of such fires in a probabilistic setting can be cumbersome, and it is often not feasible as input data are too scarce or uncertain. Furthermore, the cost of laborious risk analyses may prevent a risk assessment from actually being performed. Methods combining simple use with sufficient information output and providing an adequate risk assessment and risk improvement options are therefore valuable. Risk ranking produces estimates of relative fire risk and aggregate rankings into a single index [26].

A simple tool to consider the risk of a fire spreading has been developed. FireScore is based on an index method and the result of a master thesis [7]. Elements, which are of importance to exterior fire spread were mapped by an interview and literature study. The elements were identified, sorted, ranked and weighed. The literature for the data input was mainly from the US [17] and Australia [3], complemented by a study of the Lærdal fire [7]. Literature published in Norway and interviews of the firefighting personnel involved during the Lærdal fire provided useful material for the development of FireScore.

The index method is a risk assessment tool known in the Nordic countries for its contribution to evaluating the risk of indoor room fires, i.e. "Fire Risk Index Method - Multistorey Apartment Buildings" by Björn Karlsson [27]. The same principles for risk assessment were used to establish the FireScore tool. It addresses exposure to an exterior fire and the response of the building envelope. An index method is a semi-quantitative risk assessment method, in that it assigns grades to influential elements based on a qualitative assessment. It further combines the grades of the elements by an arithmetic process where they are assigned relative weights. The weighing of the elements can easily be adjusted depending on the area of interest. The adjustment can use the analytical hierarchy process 
(AHP) [28]. The index is a comparative value for assessing risk levels. Such an index method provides transparency and documentation, which is useful for decision makers.

FireScore is divided into two distinct parts: the first gives an indication of the exposure severity and the second indicates the robustness of the fire protective envelope. The ratio of resistance to exposure gives a total risk score to a building. A low score indicates a reduced probability of loss.

\section{MAPPING AND VISUALISATION}

A risk characterised by a number is pointless in itself. It has to be communicated in an understandable and meaningful way. Visualisation of risk using colours and maps is a common way to communicate risk, e.g. as California Fire Hazard Severity Zone Map [29]. Such maps indicate the hazard in areas based on potential natural vegetation fuels over a 30-50-year horizon and their associated expected fire behaviour and exposure to buildings. Several tools have been developed to visualise and understand the risk of wild fires. Tools such as FIREHARM [30] and a method to characterise and map wildland urban interface (WUI) fires at large scale [31] all contribute to managing the problem of wildland fires.

\subsection{Tools to facilitate registration and visualisation}

In addition to the FireScore risk tool, a tool to register exposures and building elements has been developed to collect a dataset for calculating and visualising the risk score by heatmap using Google Maps. The registration tool provides an online representation of the FireScore. It takes advantage of new technology, i.e. phones, tablets, the internet etc. It is useful in the field and enables fast and costeffective registration of larger communities. Results are stored in a database, providing vast possibilities for statistics, visualisation, reports etc.

The data collected and registered can provide an overview of an area as well as detailed identification of crucial elements for single buildings by allowing the user to examine the details further. The registration tool can be accessed in the field or in the office. If used in the field combined with the right tool, a building can be geo-located for further visualisation on a map.

The user interface has two levels of detail. The first level has general information about an area and the second has information about individual buildings.

A heatmap have been made to see if it improves understanding and visualisation of the risk calculated by FireScore. It is a visualisation layer on top of a map where areas of higher fire risk (high intensity) are coloured red and areas of lower risk appear in green [32].

Figure 4 shows how a heatmap can be applied for visualisation by implementing the risk score calculated by FireScore and registered for further input. This allows multiple scores to be gathered in a single map giving an overview of the risk in an area. By zooming in, the points spread out and the score for a specific address becomes visible.

Furthermore, drones can be useful for higher-quality inspections of tall buildings. ASTM has established a task group to develop a guide for the visual inspection of building facades using drones [33]. High-quality cameras allow for close-up views of parts of facades that otherwise cannot be seen.

This type of knowledge can be useful for area planning processes as well, i.e. to map built-up areas in need of special attention by conservationists or others.

\section{DISCUSSION}

Fire dynamics are never straightforward and in most cases simulated results that forecast the exact route of a fire are never achievable. But we do have tools that make us better able to implement risk-reducing measures and to a greater extent reduce potential losses. 

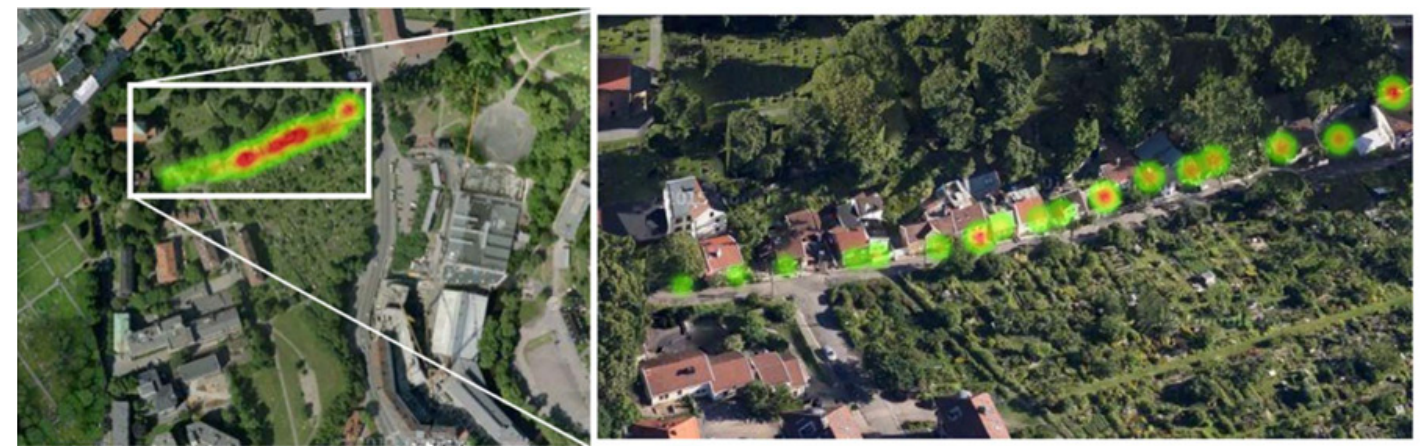

Figure 4. Application and illustration of risk visualisation by a heatmap.

An index method involves weighing elements. For exterior fire scenarios, locations and areas may differ in several respects and adjustments of the weights may, therefore, be required to obtain an adequate risk estimate. Mathematical adjustments of the element weights are simple but require professional insight, which can be obtained by a Delphi panel.

FireScore provides a risk score as a mathematical value. Changing the score changes the theoretical probability of a structure's survival. However, by mapping the index results of multiple structures in a specific area, a more accurate estimate of the risk to the community can be evaluated.

CFD tools, which simulate exterior fires, are available and useful, although they wholly depend on the input parameters. The number of parameters is hardly manageable. They are time-consuming with respect to exterior fire development and the fire spreading to the exterior envelopes of buildings. FireScore accounts for direct flame contact and heat radiation and the risk of fire spreading by firebrands linked to the exterior design of the building envelope.

The method described combined with a registration tool permits visualisation of the risk due to exposure to an exterior fire in built areas. It is not meant to simulate real events and scenarios, but to give a probabilistic picture of the situation by pinpointing critical areas, a building's details and the exposure elements.

One of the advantages of an index method is its transparency, which improves the evaluation of the risk of an exterior fire between professionals of all disciplines and owners. It also ensures that important elements are properly evaluated so that necessary measures can be taken.

Applying new technology to map built areas provides an opportunity to make statistical calculations and compare similar areas to each other. Experience thus gained can be stored in a virtual bank for later use or statistical evaluations. When events occur later in mapped areas, it is possible to learn even more about the risk by evaluating the measures that were implemented. Technology such as drones, allows for higher-quality inspections of building elements that are not visible from the ground. Nevertheless, inspections should be carried out by personnel competent in the field of exterior fires.

\section{CONCLUSION}

Decisive crucial elements that govern the development of a conflagration and WUI fires have been identified and ranked according to information based on fire-resistive performance, a literature study and interviews. Subsequently, an index method has been developed as a fire protective design tool by applying the findings. To simplify use and to add transparency, a mapping method was integrated.

A design tool was developed to provide a map of exterior fire risk in a given wild land area of multiple structures. The tool was evaluated based on exercises in pilot projects. For a user, it is a suitable tool for systematic risk assessment of the loss due to the spread of an exterior fire. The user 
may be challenged by ranking elements where site-specific conditions are not covered by the current tool. The tool identifies weak points and encourages the user to address them. Other regions may not fit the current FireScore weighing and it is recommended that expert panels with relevant knowledge specify default element weights.

\section{References}

[1] Mell, W.E., et al., The wildland-urban interface fire problem-current approaches and research needs. International Journal of Wildland Fire, 2010. 19(2): p. 238-251.

[2] NFPA, NFPA 1144 Standard for reducing structure ignition hazards from wildland fire. 2013: National Fire Protection Association (NFPA).

[3] Australian_Standard, Construction of Buildings in Bush Fire Prone Areas, in Standards Australia. 2009, Australian Standard: Australia.

[4] Steen-Hansen, A., et al., What can we learn from the Lardal fire in January 2014? Evaluation of the fire spread. (in Norwegian), in SPFR-Rapport, S.F. Research, Editor. 2014, SP Fire Research AS: Norway.

[5] Steen-Hansen, A., et al., Evaluation of fire spread in the large Lardal fire, January 2014, in Fire and Materials 2015, 14th International Conference. 2015, Interscience communications: San Francisco, USA. p. 1014-1024.

[6] PWC, Evaluation of the fires: Lardal, Flatanger og Frøya. 2014, PricewaterhouseCoopers (PWC).

[7] Jarnskjold, N.M.T., Brannskallsikring i tett trehusmiljø; English: Securing fire-protective envelopes in dense wooden built environments, in Department of Civil and Transport Engineering. 2015, Norwegian University of Science and Technology (NTNU): Norway.

[8] Ulgenes, T. Ringve Museum Fire. 2015; Available from: https ://prezi.com/vdz_khotnbth/ ringve-3-august-2015.

[9] Maranghides, A. and W. Mell, A case study of a community affected by the Witch and Guejito wildland fires. Fire technology, 2011. 47(2): p. 379-420.

[10] Per Holm Nygaard, S.S., Skogbrann og hytter, - risiko og forebygging, in Byggeindustrien. 2015: http://www. bygg.no/article/1255632.

[11] Gollner, M.J., et al., Pathways for Building Fire Spread at the Wildland Urban Interface, F.P.R. Foundation, Editor. 2015, Fire Protection Research Foundation; National Fire Protection Association NFPA: QUINCY, MASSACHUSETTS, U.S.A.

[12] Cohen, J.D. Reducing the wildland fire threat to homes: where and how much? in Proceedings of the symposium on fire economics, planning, and policy: bottom lines. 1999. San Diego, California, U.S.A.

[13] Howard, R.A., Decision Analysis of Fire Protection Strategy for the Santa Monica Mountains: An Initial Assessment: Preliminary Report. 1973: Stanford Research Institute.

[14] Maranghides, A. and W.E. Mell, Framework for Addressing the National Wildland Urban Interface Fire Problem-Determining Fire and Ember Exposure Zones Using a WUI Hazard Scale. 2012: US Department of Commerce, National Institute of Standards and Technology.

[15] Manzello, S.L., S. Suzuki, and Y. Hayashi, Enabling the study of structure vulnerabilities to ignition from wind driven firebrand showers: A summary of experimental results. Fire Safety Journal, 2012. 54: p. 181-196.

[16] Hakkarainen, T. and T. Oksanen, Fire safety assessment of wooden facades. Fire and Materials, 2002. 26(1): p. 7-27.

[17] CBSC, California Building Code, Title 24, Part 2, Chapter 7A, I.C.C. California, Editor. 2013, California Building Standard Commission. 
[18] Colwell, S. and T. Baker, Fire performance of external thermal insulation for walls of multistorey buildings: (BR 135) Third edition. Building Research Establishment Report BR135, ed. B. Trust. 2013: BRE publications.

[19] Puntabyrgi, P., Pilot project-passive exterior fire protection of small church, P. 1, Editor. 2015, Lervike AS.

[20] Van Wagner, C.E., Development and Structure of the Canadian Forest Fire Weather Index System. Forestry Technical Report. 1987, Ottawa, Canada: Canadian Forestry Service.

[21] Vicars, M. and J. Luckhurst, Firesmart: Protecting your community from wildfire. Second edition ed. 2003, Edmonton, Alberta, Canada: Partners in Protection.

[22] NFPA, Firewise Toolkit. A guide to Firewise principles, N.f.p.a.N. Firewise communities, Editor. Undated.

[23] Vicars, M. and J. Luckhurst, Firesmart: protecting your community from wildfire. Partners in Protection. Edmonton, Alberta, 1999.

[24] Maranghides, A., et al., A Case Study of a Community Affected by the Witch and Guejito Fires: Report \#2-Evaluating the Effects of Hazard Mitigation Actions on Structure Ignitions. 2013, Natianal Institute of Standards and Technology (NIST).

[25] Teague, B., R. McLeod, and S. Pascoe, Final report, 2009 Victorian bushfires royal commission. Parliament of Victoria, Melbourne Victoria, Australia, 2010.

[26] Watts, J. Criteria for fire risk ranking. in Fire Safety Science-Proceedings of the Second International Symposium. 1991. Tokyo, Japan: Hemisphere Publishing Corporation.

[27] Karlsson, B., Fire Risk Index Method - Multistorey Apartment Buildings, FRIM-MAB Version 2.0. Report P0212053, Trätek AB, Stockholm, 2002.

[28] Saaty, T.L., How to make a decision: the analytic hierarchy process. European journal of operational research, 1990. 48(1): p. 9-26.

[29] FIRE, C., California Fire Hazard Severity Zone Map Update Project, T.C.D.o.F.a.F. Protection, Editor. 2007, CAL FIRE: http: //www. ca.gov.

[30] Keane, R.E., et al., A method for mapping fire hazard and risk across multiple scales and its application in fire management. Ecological Modelling, 2010. 221(1): p. 2-18.

[31] Lampin-Maillet, C., et al., Mapping wildland-urban interfaces at large scales integrating housing density and vegetation aggregation for fire prevention in the South of France. Journal of Environmental Management, 2010. 91(3): p. 732-741.

[32] Developers, G., Heatmap Layer. Google: https://developers.google.com/maps/ documentation/javascript/heatmaplayer.

[33] ASTM. New ASTM Standards Aim to Help with Building Facade Inspections, Including Drone Use. 2016 [cited 2016 08.01.2016]. 